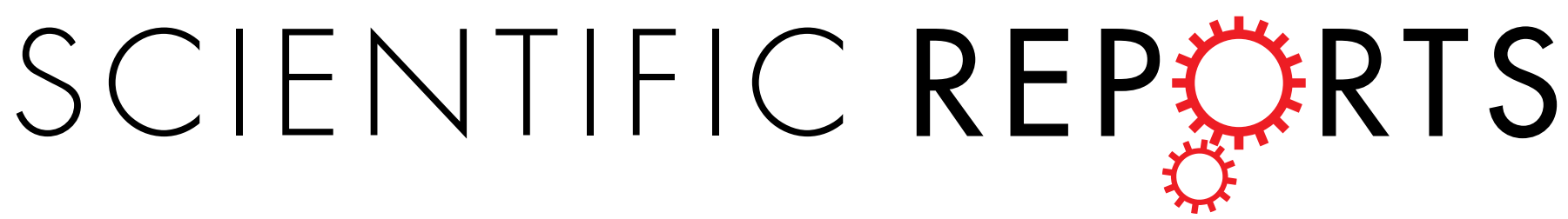

\title{
Corrigendum: Dynamics of microdroplets over the surface of hot water
}

Takahiro Umeki, Masahiko Ohata, Hiizu Nakanishi \& Masatoshi Ichikawa

Scientific Reports 5:8046; doi: 10.1038/srep08046; published online 27 January 2015; updated 15 July 2015

This Article contains typographical errors in Figure 4. In Figure 4a, the 'degree' symbols were omitted from the temperatures of the droplet radii. The $\mathrm{x}$-axis 'Radius $(\mathrm{m})$ ' should also read 'Radius $(\mu \mathrm{m})$ '. In Figure 4b, the $\mathrm{x}$-axis 'Temperature (C)' and y-axis 'Average Radius (m)' should also read 'Temperature $\left({ }^{\circ} \mathrm{C}\right)$ ' and 'Average Radius $(\mu \mathrm{M})$ ' respectively. The correct Figure 4 appears below as Figure 1.
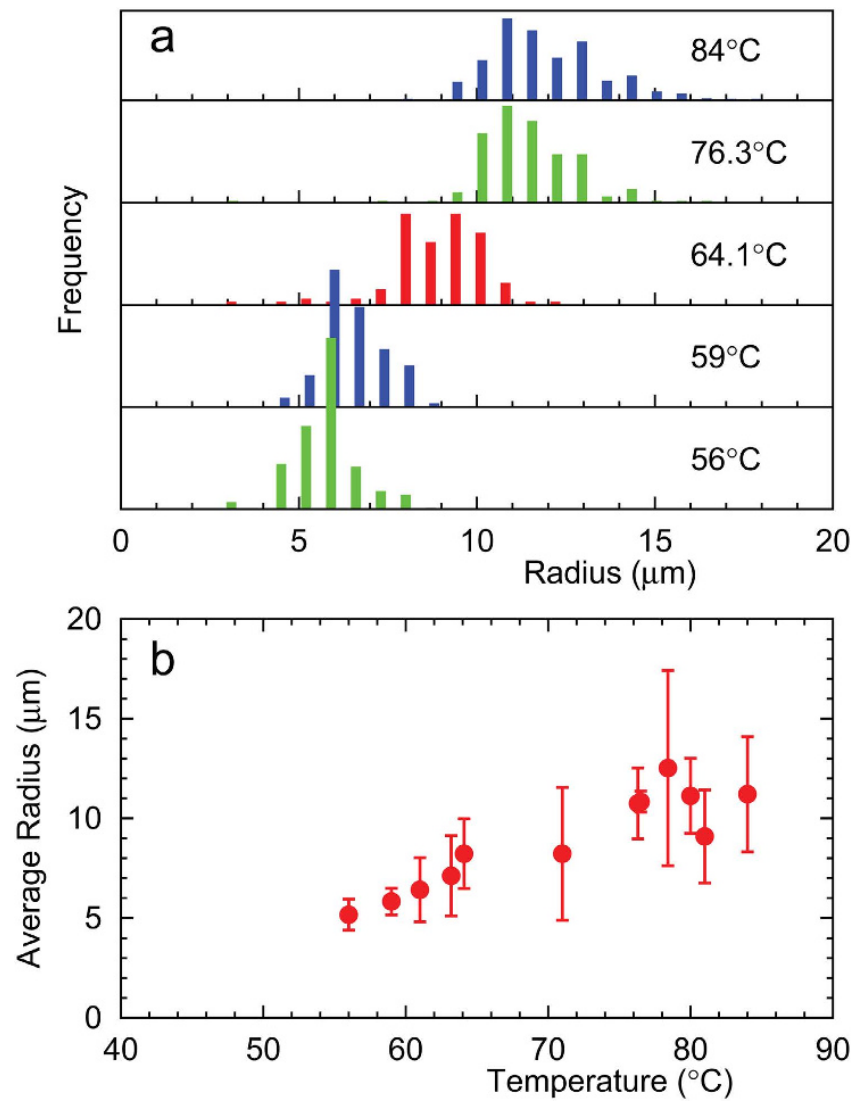

Figure 1. 